\title{
Double blind trial of ionisers in children with asthma sensitive to the house dust mite
}

\author{
J A Warner, J L Marchant, J O Warner
}

\begin{abstract}
Background-Manufacturers of ionisers claim many benefits from the use of their devices, including the relief of asthma. Particles removed from the air are likely to include airborne allergens, so ionisers may achieve an effect by reducing the allergen load.
\end{abstract}

Methods-The effect of ionisers on airborne concentrations of house dust mite allergen Der $p$ I was investigated in a double blind, crossover, placebo controlled trial in the homes of 20 children with allergic asthma. Subjects recorded their peak expiratory flow rate (PEFR) twice daily and completed a daily symptom score and treatment schedule on a diary card for two six week periods, one with an active ioniser and the other with a placebo ioniser (randomly allocated) used in the living room and the bedroom. Results-Airborne Der $p$ I concentrations fell significantly during the active period compared with the placebo period, but there was no significant change in PEFR, symptom scores, or treatment usage. There was an increase in night time cough which almost reached significance during the active period.

Conclusions-This study indicates that the use of ionisers cannot be recommended in the homes of asthmatic subjects to improve their symptoms. The significant reduction of airborne allergen concentrations may be of use as part of a multidevice allergen avoidance regimen, but the increase in night time cough requires further study.

(Thorax 1993;48:330-333)

University Child Health, Southampton General Hospital, Southampton SO9 4XY

$\mathrm{J} A$ Warner

J O Warner

Paediatric

Department, Royal

Brompton National

Heart and Lung

Hospital, London SW3 6HP

J L Marchant

Reprint requests to: Dr J A Warner

Received 10 August 1992 Returned to authors 22 October 1992 Revised version received 29 October 1992

Accepted 5 November 1992 is readily demonstrable, the relief of asthma is questionable. There have been several uncontrolled studies to investigate the effect on asthma, some showing temporary improvement in symptoms on exposure to negatively charged ions ${ }^{1-4}$ and others showing no effect. ${ }^{5}$ Only two studies have investigated the ionisation of air under controlled conditions. ${ }^{6-7}$

Ben-Dov et $a l^{6}$ showed a significant attenu- ation in exercise induced asthma in patients breathing negatively ionised compared with non-ionised air, but there was no effect on the response to histamine. Nogrady and Furness could find no effect of ionisers on PEFR, symptom score, or consumption of medications during a blind crossover study of active and placebo ionisers in adults with asthma. ${ }^{7}$ No studies have established whether ionisers reduce aeroallergen load coincident with clinical monitoring.

This study investigated the efficiency of ionisers in reducing airborne house dust mite allergen $(\operatorname{Der} p \mathrm{I})$ in the homes of children with house dust mite induced asthma and the effect of reduced concentrations of the allergen on their symptoms.

\section{PATIENTS}

Twenty children with perennial asthma of median age 9 (range 3-11) years were selected from the Brompton Hospital asthma clinic. All children had a skin test reactivity of greater than or equal to $3 \mathrm{~mm}$ weal diameter when tested with standard house dust mite skin test solution (Dome Hollister Stier, 1200 $\mathrm{PNU} / \mathrm{ml}$ ) and were regular attenders at the asthma clinic for management of their asthma.

ANALYSIS OF HOMES

The airborne allergen content of patients' homes was assessed before enrolment into the study and only those with $\operatorname{Der} p$ I concentration in both the living room and the child's bedroom of greater than $2 \mathrm{ng} / \mathrm{m}^{3}$ air were enrolled.

Air sampling was performed as described previously. ${ }^{8}$ The Casella personal sampler (Casella, Bedford, UK) sampling $21 / \mathrm{min}$ was used for measurement of airborne $\operatorname{Der} p \mathrm{I}$. Three hour samples were collected in duplicate for each patient from the child's bedroom and from the living room in which the child spent most time. Normal domestic activities such as walking around the room and sitting on the furniture were in progress in the houses during the sampling periods, but dusting, vacuuming, and bedmaking were avoided.

\section{FILTER EXTRACTION}

The Casella personal sampler collects particulate matter onto a glass fibre filter that retains particles larger than $5 \mu \mathrm{m}$ in diameter (Whatman, UK). For allergen determination the complete personal filter $(25 \mathrm{~mm})$ was extracted overnight with $1 \mathrm{ml}$ PBS/Tween 
$0.5 \%$ (BDH, Poole, UK) with $0.2 \%$ bovine serum albumin (BDH) followed by sonication and filtration through a $0.2 \mu \mathrm{m}$ filter (Whatman). Eluted samples were stored at $-20^{\circ} \mathrm{C}$ until required for assay.

\section{MEASUREMENT OF ALLERGENIC ACTIVITY BY ELISA}

The level of $\operatorname{Der} p$ I was measured using the ALK (Denmark) ELISA system incorporating affinity purified monospecific antibody to Der $p$ I according to the manufacturer's instructions. The assay was able to detect levels of $\operatorname{Der} p$ I above $1 \mathrm{ng} / \mathrm{ml}$ with an upper limit of $85 \%$ of the maximal response $(340 \mathrm{ng} / \mathrm{ml})$. The intra-assay variation was approximately $5.4 \%$ and the interassay variation about $14 \%$.

\section{IONISERS}

The ionisers used in the study were Clear Air ionisers provided by $\mathrm{Mr} \mathrm{J}$ Cleary of the London Ioniser Centre.

\section{STUDY DESIGN}

The trial was of a double blind crossover design. After the initial home visit to determine airborne allergen concentrations, the selected homes were randomly allocated to two groups of 10: (a) active period (six weeks) first, and (b) placebo period (six weeks) first. Air sampling was performed at the beginning, middle, and end of each ioniser period, and the ionisers were changed after the final sampling of the first period. Subjects were assessed by diary cards on which they recorded symptom scores, medication, and PEFR as measured with a Wright peak flow meter (in those children who could perform reproducible blows). PEFR was recorded before breakfast and bedtime medicines, the best of three blows on each occasion being measured. Symptoms were scored as follows: wheeze last night (0-3), cough last night $(0-3)$, wheeze today $(0-3)$, activity today (0-3), sputum production (0-2). Consumption of inhaled or oral bronchodilators, corticosteroids, sodium cromoglycate,

Table 1 Comparison of changes in airborne Der $\mathrm{p} I$ levels during active and placebo ioniser periods

\begin{tabular}{|c|c|c|}
\hline & $\begin{array}{l}\text { Increased or } \\
\text { unaltered Der } \mathrm{p} I\end{array}$ & $\begin{array}{l}\text { Decreased } \\
\text { Der p I }\end{array}$ \\
\hline $\begin{array}{l}\text { Active } \\
\text { Placebo }\end{array}$ & $\begin{array}{l}11 \\
33\end{array}$ & $\begin{array}{r}29 \\
7\end{array}$ \\
\hline
\end{tabular}

$\mathrm{p}<0.01$ ( $\chi^{2}$ test)

Table 2 Mean (SE) daily score after last three weeks of each six week ioniser period of PEFR (I/min), symptom scores, and medication scores in 14 subjects

\begin{tabular}{llll}
\hline & \multicolumn{1}{c}{ Active } & Placebo & $p$ (Wilcoxon rank sum test) \\
Morning PEFR & $232.6(23.4)$ & $231.3(25.8)$ & 0.826 \\
Evening PEFR & $239.2(24.5)$ & $232.8(26.1)$ & 0.187 \\
Night time wheeze & $0.19(0.08)$ & $0.198(0.07)$ & 0.896 \\
Daytime wheeze & $0.20(0.07)$ & $0.185(0.09)$ & 0.554 \\
Night time cough & $0.43(0.19)$ & $0.139(0.04)$ & 0.055 \\
Daytime activity & $0.06(0.03)$ & $0.06(0.04)$ & 1.0 \\
Medication & $0.48(0.18)$ & $0.53(0.25)$ & 0.275 \\
\hline
\end{tabular}

PEFR-peak expiratory flow rate. and other medications was also recorded. All subjects were asked to record the data throughout the whole 12 week period. For each ioniser period they were asked to use the device in the living room during the day and the child's bedroom at night. It was not possible for the families or the investigators to determine whether the ioniser was active or placebo as both appeared identical, the only difference being that the placebo devices had no internal wiring and had been coded by the manufacturer.

Mean morning and evening PEFRs were calculated for each period for each subject able to perform the tests $(n=14)$. Symptoms and bronchodilator use were scored as outlined above and mean scores for each period were calculated.

The study was approved by the Joint Ethical Committee of the Brompton Hospital and the National Heart and Lung Institute.

\section{STATISTICAL ANALYSIS}

Statistical analysis was performed to compare active and placebo periods using the Wilcoxon signed rank sum test for the clinical observations, and the $\chi^{2}$ and Mann-Whitney $\mathrm{U}$ tests for the allergen measurements.

\section{Results}

\section{Der $p$ I CONCENTRATIONS}

The changes in airborne $\operatorname{Der} p$ I concentrations during the active and placebo ioniser periods in the living rooms and bedrooms of the 20 houses are shown in the figure. There was a significant $(p<0.0001$, Mann-Whitney $\mathrm{U}$ test) decrease in airborne $\operatorname{Der} p$ I concentrations in both bedrooms and living rooms during the active period compared with the placebo period. Table 1 summarises the changes.

\section{CHANGES IN PEFR}

PEFR values were reproducibly recorded in 14 children throughout the two ioniser periods. Table 2 shows the mean values which were not significantly different between the periods.

\section{SYMPTOM SCORES}

There were no significant differences in any symptom scores between the two periods There was, however, a trend towards there being an increased night time cough during the active ioniser period (table 2 ) which was very close to significance $(p=0.055)$.

\section{MEDICATION}

No significant difference was seen in bronchodilator usage between the two periods (table 2).

\section{Discussion}

Families with an asthmatic child are extremely susceptible to advertising in the media which suggests they can purchase a device that will reduce the likelihood that an asthma attack will be triggered. An ioniser which is claimed to remove dust from the air would 
Changes in airborne Der $\mathrm{p} I$ concentrations $\left(n g / \mathrm{m}^{3}\right)$ in the living room $(A)$ and bedroom $(B)$ of 20 children after six weeks use of an active ioniser and six weeks use of a placebo ioniser.
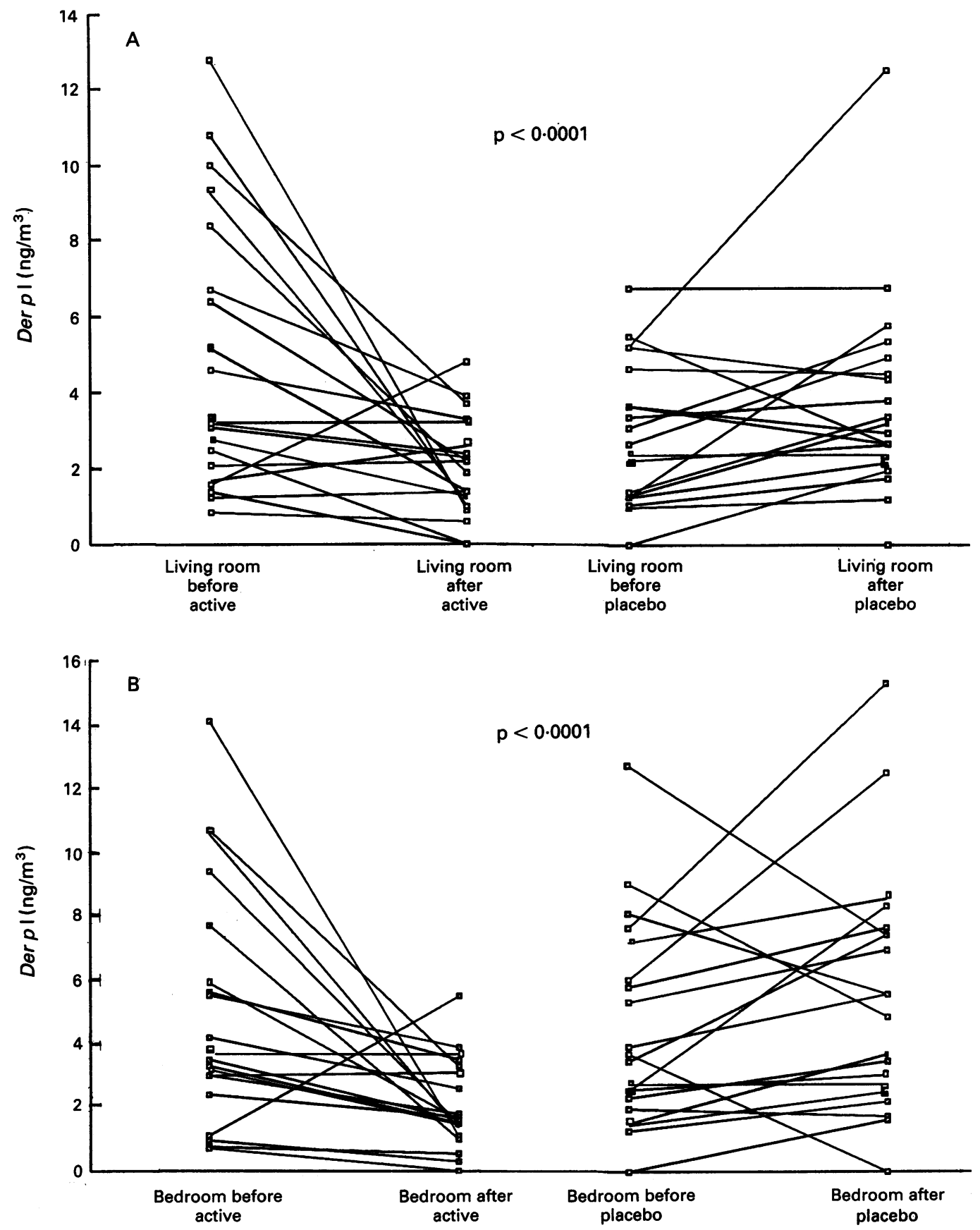

seem a very likely candidate for reducing exposure to allergens such as the house dust mite allergen (Der $p \mathrm{I}$ ), the cat allergen ( Fel $d \mathrm{I}$ ), and grass pollen grains which are known to be present on airborne particles. It is claimed that all airborne particles given a negative charge fall to the nearest earthed surface (usually the floor). They could then be removed by vacuuming, thus reducing the allergen content of the room. Other studies ${ }^{69}$ suggest that the effect of ionisation is to slow the rate of fluid evaporation from the lung mucosa, thus reducing heat loss which is an important mechanism in exercise induced asthma, but this has not been proved.

Most studies of ionisation have been extremely short ${ }^{1-4}$ with only two longer term studies, one of which ${ }^{10}$ had only seven patients and did not randomise the order in which the active and placebo ionisers were used. There was also a longer active period (eight weeks) than placebo period (four weeks). This study did find a significant improvement in PEFR during the active period. The other investigation ${ }^{7}$ was a double blind crossover with placebo in 20 adults and failed to show any statistical benefit of negative ion generators in asthmatic subjects. They were also unable to show any decrease in airborne dust, but their method of detection was not described.

As the house dust mite is the single most common trigger of allergy in children and $85 \%$ of children with asthma are allergic, this study aimed to investigate the effect of ionisation on the concentration of $\operatorname{Der} p I$, and the effect of any alteration in this on asthmatic symptoms. The highly significant reduction in airborne $\operatorname{Der} p$ I during the active ioniser period would appear extremely encouraging for those considering allergen avoidance. Even in the homes where the reduction was 
most dramatic, however, there was no measurable improvement in asthma symptoms and it must also be noted that in a few houses there was actually an increase in $\operatorname{Der} p \mathrm{I}$ in the air while the active ioniser was present.

There are many explanations for the lack of improvement in asthma symptoms. Because of the chronic inflammatory processes involved in asthma, six weeks may not be long enough to show changes in symptoms as a result of environmental manipulation. The home is not the only environment to which the children are exposed. Studies from Norway ${ }^{1112}$ have shown that children are also exposed to measurable levels of domestic allergens (house dust mite, cat, and dog) at school which may have a considerable effect on their symptoms. Allergens are released in large quantities from beds, carpets, and soft furnishings when they are disturbed and it has not yet been satisfactorily determined whether asthma symptoms are attributable to a long term average exposure to airborne allergens or to an intermittent exposure to high levels in dust clouds. Our results show that an ioniser is capable of reducing the background airborne allergen levels when little disturbance is occurring, but it may have no effect on intermittent exposure to high levels. This short duration, high level exposure may be enough to allow symptoms to persist. It is possible that ioniser equipment with a higher ion output than that used in this study might be more effective at controlling dust clouds, but this could only be established by conducting a similar controlled trial.

In those homes where airborne allergen levels increased during the active period it must be assumed that the ionisers interacted with the charge already existing within the room to allow more particles to remain airborne. This did not increase the children's symptoms, lending further support to the importance of short duration exposure levels.

The increase in night time cough while using the active ionisers came very close to significance. It has been suggested that this could be caused by the irritant effect on the airways of ozone produced by ionisers. This particular ioniser model, however, could not be shown to be producing measurable ozone when tested with Kitigawa Precision Gas Detector equipment in the rooms under study. It has also been suggested that charged ions can be irritant to airways in their own right and there is a considerable rise in ion counts in a room during the operation of an active ioniser. ${ }^{7}$ This is more likely to be a problem at night in an undisturbed bedroom where the ions are not dissipated and, indeed, where the door may be closed.

These results would not allow recommendation of ionisers of the type used in this study for relief of asthma symptoms despite their significant effect on airborne house dust mite concentrations. It may be worth noting, however, that three parents reported relief of rhinitis symptoms during the study and when investigated this relief was during the active period in each case. It is possible that such an approach could be used as an integral part of a much more complex allergen avoidance regimen where other techniques are used simultaneously to reduce the allergen concentrations in dust reservoirs such as beds and soft furnishings that produce the allergen clouds uncontrolled by an ioniser alone. Nevertheless, the effect on cough needs further investigation before such a recommendation could be made.

We would like to thank Dr Tara Assadullahi and Miss Sally Little for their help in visiting the homes for air sampling and Mrs Brenda Colwell for typing the manuscript.

Komblueh IH, Griffin JE. Artificial air ionisation in physical medicine. Am f Phys Med 1955;34:618-24.

2 Kornblueh IH, Piersol GM, Speicher FP. Relief of pollenosis in ionised rooms. Am $F$ Phys Med 1958; 7:18-27.

3 Zylberg B, Loveless MH. Preliminary experiments with ionised air in asthma. $\mathcal{F}$ Allergy 1960;31:370-8.

4 Palti Y, De Nour E, Abrahamor A. The effect of atmospheric ions on the respiratory system of infants. Pediatrics 1966;38:404-11.

5 Kreuger AP. Air ions and physiological function. $f \mathrm{Gen}$ Physiol 1962;45:233-4.

6 Ben-Dov I, Amirar I, Shochina M, Auritai I, Bar-Yishay E, Godfrey S. Effect of negative ionisation of inspired air on the response of asthmatic children to exercise and inhaled histamine. Thorax 1983;38:584-8.

7 Nogrady SG, Furnass SB. Ionisers in the management of bronchial asthma. Thorax 1983;38:919-22.

8 Warner JA, Little SA, Pollock I, Longbottom JL, Warner JO. The influence of exposure to house dust mite, cat pollen and fungal allergens in the home on primary sensitisation in asthma. Pediatr Allergy Immunol 1991;1: 79-86.

9 Hart FX, Bachman $\mathrm{CH}$. The effect of air ions on liquid evaporation rates. Int $\mathcal{f}$ Biometerol 1981;12:251-61.

10 Jones DP, O'Connor SA, Collins JV, Watson BW. Effect of long term ionised air treatment on patients with bronchial asthma. Thorax 1976;31:428-32.

11 Dybendal T, Hetland T, Vik H, Apold J, Elsayed S. Dust from carpeted and smooth floors I. Comparative measurements of antigenic and allergic proteins in dust vacuumed from carpeted and non-carpeted classrooms in Norwegian schools. Clin Exp Allergy 1989;19:217-24.

12 Dybendal T, Vik H, Elsayed S. Dust from carpeted and smooth floors II. Antigenic and allergenic content of dust vacuumed from carpeted and smooth floors in schools under routine cleaning schedules. Allergy 1989; 44:401-11. 